\title{
Sociopsychological Tailoring to Address Colorectal Can- cer Screening Disparities: A Randomized Controlled Trial
}

\author{
Anthony Jerant, MD \\ Richard L. Kravitz, MD, MSPH \\ Nancy Sobler, PbD, MPH \\ Kevin Fiscella, MD, MPH \\ Raquel L. Romero, MD, MPH \\ Bennett Parnes, MD \\ Daniel J. Tancredi, PbD \\ Sergio Aguilar-Gaxiola, MD, PbD \\ Christina Slee, MPH \\ Simon Dvorak, BA \\ Charles Turner, $\mathrm{PbD}$ \\ Andrew Hudnut, MD \\ Francisco Prieto, MD \\ Peter Franks, MD
}

Conflicts of interest: authors report none.

\section{CORRESPONDING AUTHOR}

Anthony Jerant, MD

Department of Family and Community Medicine

UC Davis School of Medicine

4860 Y St, Suite 2300

Sacramento, CA 95817

afjerant@ucdavis.edu

\begin{abstract}
PURPOSE Interventions tailored to sociopsychological factors associated with health behaviors have promise for reducing colorectal cancer screening disparities, but limited research has assessed their impact in multiethnic populations. We examined whether an interactive multimedia computer program (IMCP) tailored to expanded health belief model sociopsychological factors could promote colorectal cancer screening in a multiethnic sample.
\end{abstract}

METHODS We undertook a randomized controlled trial, comparing an IMCP tailored to colorectal cancer screening self-efficacy, knowledge, barriers, readiness, test preference, and experiences with a nontailored informational program, both delivered before office visits. The primary outcome was record-documented colorectal cancer screening during a 12-month follow-up period. Secondary outcomes included postvisit sociopsychological factor status and discussion, as well as clinician recommendation of screening during office visits. We enrolled 1,164 patients stratified by ethnicity and language (49.3\% non-Hispanic, $27.2 \%$ Hispanic/English, 23.4\% Hispanic/Spanish) from 26 offices around 5 centers (Sacramento, California; Rochester and the Bronx, New York; Denver, Colorado; and San Antonio, Texas).

RESULTS Adjusting for ethnicity/language, study center, and the previsit value of the dependent variable, compared with control patients, the IMCP led to significantly greater colorectal cancer screening knowledge, self-efficacy, readiness, test preference specificity, discussion, and recommendation. During the followup period, 132 (23\%) IMCP and 123 (22\%) control patients received screening (adjusted difference $=0.5$ percentage points, $95 \% \mathrm{Cl}-4.3$ to 5.3 ). IMCP effects did not differ significantly by ethnicity/language.

CONCLUSIONS Sociopsychological factor tailoring was no more effective than nontailored information in encouraging colorectal cancer screening in a multiethnic sample, despite enhancing sociopsychological factors and visit behaviors associated with screening. The utility of sociopsychological tailoring in addressing screening disparities remains uncertain.

Ann Fam Med 2014;204-214. doi: 10.1370/afm.1623.

\section{INTRODUCTION}

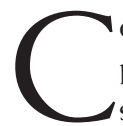
olorectal cancer screening is underutilized. ${ }^{1,2}$ Screening rates are particularly low among Hispanic persons, reflecting language and socioeconomic barriers. ${ }^{1,3}$ Approaches to motivate more individuals to undergo colorectal cancer screening and lessen ethnic screening disparities are needed.

Interventions tailored to sociopsychological factors that may influence behavior, such as self-efficacy, stage of readiness, barriers, and others, ${ }^{4}$ show promise. ${ }^{5}$ Such interventions use responses elicited from individuals to match the content and amount of information to individual needs and sociopsychological factors, with the proximate goal of enhancing the factors. ${ }^{6-8}$ Tailoring of information increases its perceived relevance, promotes deeper cognitive processing, and improves recall. ${ }^{9}$ Further, in randomized controlled trials tailored interventions are more effective than nontailored 
interventions in enhancing sociopsychological factors across sociodemographic groups. ${ }^{10-22}$

Whether enhancement of sociopsychological factors influences health behaviors is uncertain. ${ }^{12,13,19,22-32}$ Among trials comparing patients receiving sociopsychologically tailored colorectal cancer screening interventions with active control, $15,19,20,22,25-30,33$ only some found superior effects of tailoring ${ }^{19,25,28,29,34} ;$ in all but 1 trial $^{34}$ screening was self-reported, ${ }^{19,25,28,29}$ suggesting possible response bias. There is a need to examine further whether objectively measured colorectal cancer screening improves in response to sociopsychological tailoring.

Such interventions could also reduce ethnic disparities in health behaviors. ${ }^{8}$ One randomized controlled trial included sociopsychological tailoring in a multifaceted study of colorectal cancer screening in Hispanic and Asian-American racial/ethnic groups. ${ }^{25}$ That study found increased screening in both racial/ethnic groups, but it did not compare effects between these groups, and screening was self-reported. The multifaceted nature of the study precluded determination of tailoring effects specifically.

In a multicenter randomized controlled trial, we compared the effects of 2 patient-focused colorectal cancer screening interventions delivered before office visits. The first was an interactive multimedia computer program (IMCP), tailored to expanded health belief model (EHBM) factors associated with screening: knowledge, self-efficacy, barriers, readiness, test preference, and prior screening. ${ }^{4}$ Proximate aims were to enhance sociopsychological factors, motivating patients for screening and to encourage discussion of screening, and prompting clinicians to recommend screening. ${ }^{35}$ The second intervention was a nontailored program providing basic screening information. The primary outcome was colorectal cancer screening during a 12-month follow-up period, ascertained by record review. Randomization was stratified by ethnicity and language (non-Hispanic, Hispanic/English, or Hispanic/Spanish). We hypothesized that the tailored IMCP would be more effective than control in (1) favorably influencing the sociopsychological factors, (2) prompting discussion and clinician recommendation of screening, and (3) promoting screening. Further, given the relevance of EHBM factors across sociodemographic groups, ${ }^{25,36}$ we hypothesized IMCP effects would not differ by ethnicity or language.

\section{METHODS}

Study activities were conducted from February 1, 2010, to November 30, 2012. Institutional review board approval was obtained at all performance sites.
Study Setting, Recruitment, and Randomization

Patients aged 50 to 75 years and not up-to-date for colorectal cancer screening were recruited from primary care offices in Sacramento, California (10 offices, 9 in a university-affiliated network); the Bronx (1 federally qualified health center [FQHC]) and Rochester (2 FQHCs, 1 hospital-based practice), New York; San Antonio, Texas (2 FQHCs, 2 private practices); and Colorado (1 FQHC near Denver, 7 in a FQHC system 200 miles southwest of Denver). A sample size of 1,344 patients was targeted, approximately equally divided among 4 ethnicity/intervention subgroups (Hispanic/ experimental, Hispanic/control, non-Hispanic/experimental, non-Hispanic/control). Anticipating 10\% attrition, this sample size was estimated to yield $80 \%$ power to detect 10 percentage point differences in screening on pairwise between-subgroup comparisons.

At all but 1 site initial study eligibility was determined by medical record review. Patients were considered up-to-date for screening (and therefore ineligible) if 1 or more of the following was documented: fecal occult blood test (FOBT) within 1 year, flexible sigmoidoscopy within 5 years, or colonoscopy within 10 years. ${ }^{2,37}$ Persons meeting initial eligibility criteria were solicited for participation, primarily by telephone and secondarily by letters inviting a call to the recruitment line.

Additional eligibility required the ability to speak and read English or Spanish and adequate eyesight, hearing, and hand function to use a touchscreen computer. Eligible patients agreeing to participate were asked to arrive 1 hour before an appointment they had previously scheduled with their clinician so they could complete informed consent and the intervention. At the Bronx site, for feasibility reasons, recruitment personnel instead approached patients in the waiting area before their appointments, with study eligibility based on self-report.

Patients were given touchscreen notebook computers to use before and after their visit. Research assistants logged the patients into the study software and showed them how to navigate the program. After answering ethnicity (Hispanic or non-Hispanic) and preferred software language (English or Spanish) questions, patients were randomly assigned by the software to receive either the tailored IMCP or control program in their preferred language. Randomization was stratified by ethnicity and language and implemented in blocks of 10 within each stratum, using a random number generation program. ${ }^{38}$ Patients received a $\$ 20$ gift card or cash after completing a postvisit questionnaire.

\section{Study Interventions}

We designed the study computer programs using standard software engineering principles. ${ }^{39}$ The design 
elements (eg, architecture, operating systems, usability features) have been described elsewhere. ${ }^{40}$

For patients receiving the experimental tailored IMCP, the computer algorithm for presenting tailored messages, including a specific colorectal cancer screening test recommendation based on EHBM measure responses, was developed using a previously described approach. ${ }^{41}$ The IMCP used sequential tailoring. An initial module assessed and then provided tailored information to increase knowledge of colorectal cancer screening tests (Figure 1, boxes E2 and E2a). The next module assessed and provided tailored information to increase knowledge of screening harms and inconveniences (Figure 1, boxes E3 and E3a). The final module assessed self-efficacy, barriers, readiness, test preference, and screening history (Figure 1, box E4), and then provided tailored information to enhance self-efficacy, barriers, and readiness (Figure 1, boxes E4a, E4b, and E4c). The approach of addressing knowledge gaps before trying to influence other EHBM factors was grounded in research regarding the promotion of informed decisions. ${ }^{42}$ Previsit EHBM measures were administered sequentially so that responses to each would still be fresh in patients' minds when they viewed information tailored to the responses. Consistent with adult learning and behavioral theory, the IMCP allowed patients to decide how much information to view. ${ }^{6,43-45}$ The texts for the English and Spanish IMCP versions (average Flesch-Kincaid reading grade level 7.4) were developed by a previously described process..$^{40,46}$ Examples of tailored IMCP content are available from the authors.

For the nontailored control program, after first completing all previsit study measures, control participants viewed nontailored colorectal cancer screening information, developed by the National Cancer Institute, in their preferred language (English or Spanish) (Figure 1, boxes $\mathrm{C} 1$ through $\mathrm{C} 4$, and $\mathrm{C} 5$, respectively). ${ }^{47,48}$

\section{Measures}

EHBM sociopsychological factors were measured pre- and postvisit. As noted previously, the timing of previsit measures differed somewhat between the study intervention groups (Figure 1). Preference for a colorectal cancer screening test was assessed with a single, newly developed item (response options: do not want screening, prefer FOBT, prefer colonoscopy, prefer another test, or want screening but no specific test preferred)..$^{10}$ Knowledge of screening test options was measured with a 3 -item scale, with true (1 point) vs false/don't know ( 0 points) responses (scores ranged from 0 to 3, with higher scores indicating greater knowledge). ${ }^{10}$ Knowledge of screening risks and inconveniences (scores ranged from 0 to 6 ) was measured with a 6 -item scale, using true (1 point) vs false/don't know (0 points) responses. ${ }^{10}$ Both screening knowledge scales were modeled on previously validated scales for assessing patient knowledge of health issues. ${ }^{49}$

Colorectal cancer screening self-efficacy was measured using a 6 -item scale ${ }_{i} 3$ items had been validated, ${ }^{50}$ and 3 were modeled on previously validated items. ${ }^{51}$ Barriers to FOBT and colonoscopy were measured with validated 9- and 10-item scales, respectively. ${ }^{52}$ In the self-efficacy and barriers scales, respondents indicated their degree of agreement or disagreement with statements $(1=$ strongly disagree to $5=$ strongly agree). Item responses were averaged to yield total scores (range from 1 to 5, with higher scores indicating higher selfefficacy or fewer barriers). FOBTs and colonoscopy stage of readiness (precontemplation, contemplation, preparation) were measured using modifications of a validated item. ${ }^{53}$ Prior FOBT and colonoscopy testing each were assessed with newly developed items (received vs not received/unsure).

Participants were asked whether screening was discussed during the visit and whether the clinician recommended screening (yes vs no/don't recall).

Colorectal cancer screening (FOBT, flexible sigmoidoscopy, or colonoscopy) during 12 months of follow-up was ascertained by review of electronic and paper medical records. Data collection personnel were not alerted to participants' study group.

In addition to ethnicity and language (both assessed before initial randomization), several other participant characteristics were assessed at baseline to verify that the intervention groups were well matched on characteristics that could influence screening. Sociodemographic characteristics included age, sex, race (white, black, or other), income (less than $\$ 10,000, \$ 10,000$ to less than $\$ 15,000, \$ 15,000$ to less than $\$ 25,000, \$ 25,000$ to less than $\$ 50,000$, or greater than $\$ 50,000$ ), and education (less than high school, some high school, high school graduate, some college, or college graduate). Self-reported health literacy was assessed using a single item (scored from 1 to 5, with higher scores indicating worse literacy). ${ }^{54}$ Health status was measured with the SF-12 Health Survey mental and physical component summaries (scored from 0 to 100, with higher scores indicating better health). ${ }^{55} \mathrm{~A}$ single item assessed length of the clinician-patient relationship (less than 1 year, 1 to 2 years, 3 to 5 years, more than 5 years, or unsure).

Satisfaction with the intervention was assessed using a 5 -item scale (scored from 1 to 5 , with higher scores indicating greater satisfaction). Study software use time in minutes was extracted from program logs.

\section{Data Analysis}

Data were analyzed using Stata 12.1 (StataCorp).

Descriptive comparisons used $\chi^{2}$ tests (categorical 


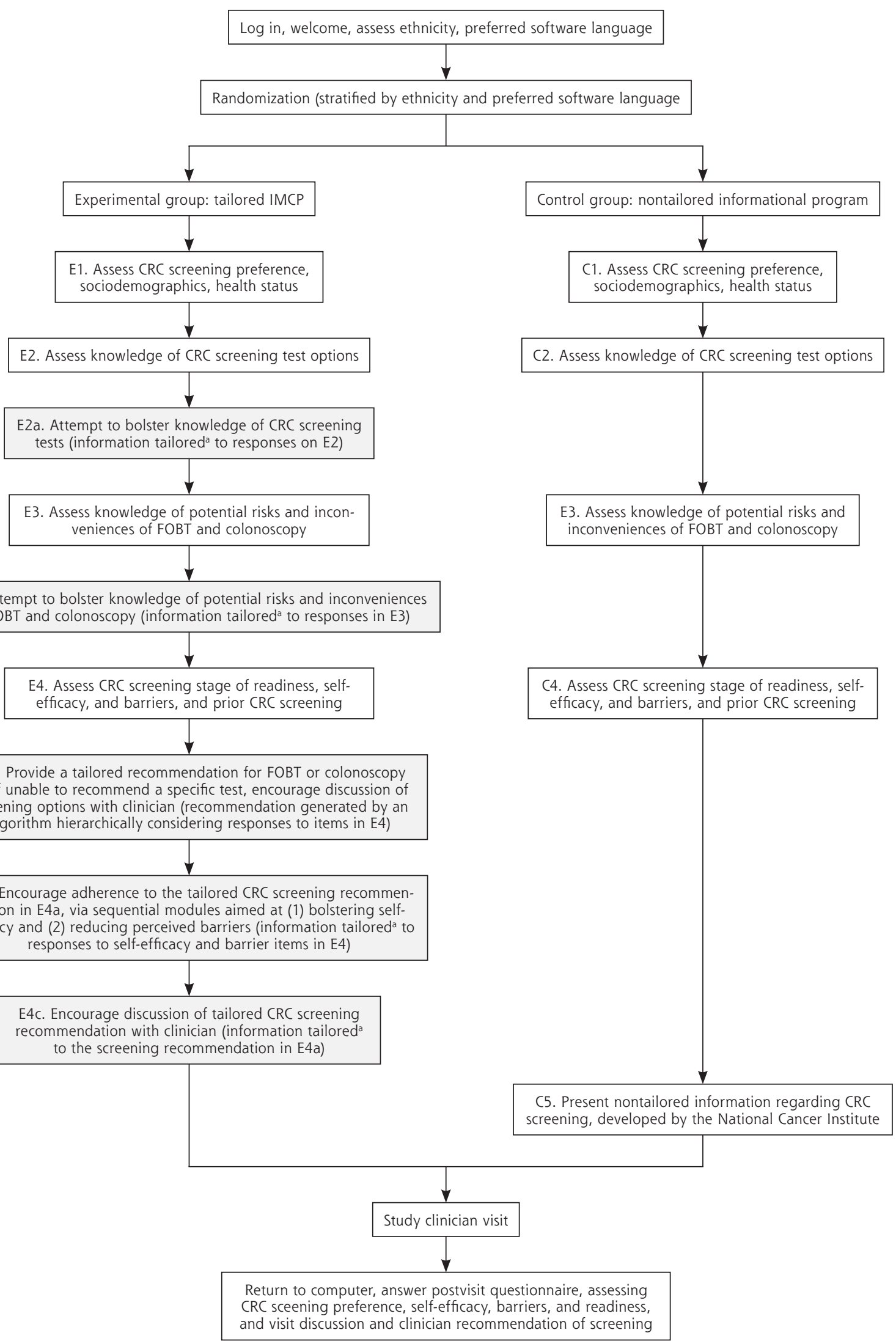


variables) and $t$ tests (continuous variables). In examining the effects of the key predictor (experimental vs control intervention) on postvisit status of sociopsychological factors and visit behaviors (the dependent variables), we used logistic regression for screening preference (preference for a specific test [FOBT or colonoscopy] vs no specific test preference), discussion of screening (vs no discussion), and clinician recommendation for screening (vs no recommendation). We used ordinal logistic regression to examine intervention effects on stage of readiness (most favorable stage from FOBT and colonoscopy readiness items [precontemplation, contemplation, or preparation]), whereas we used linear regression for screening knowledge (test options and risks/inconveniences scores combined), self-efficacy, and barriers. We analyzed the association of study intervention condition with screening with logistic regression (received FOBT and/ or colonoscopy by 12 months or not) and Cox proportional hazards models (time to screening, censoring at 12 months). All of the above analyses were adjusted for study recruitment center and ethnicity/language strata (non-Hispanic, Hispanic/ English, and Hispanic/Spanish). The sociopsychological factor models were additionally adjusted for the previsit value of the dependent variable.

To explore whether intervention effects varied by ethnicity/preferred language, further models added experimental intervention*ethnicity/preferred language interaction terms. Additional models stratified by ethnicity/preferred language were also fit.

\section{RESULTS}

Figure 2 shows the flow of participants through the study. We randomized 1,164 patients
(49.3\% non-Hispanic, 27.2\% Hispanic/English, 23.4\% Hispanic/Spanish). There were no significant differences between study groups on previsit patient characteristics or intervention use time or satisfaction (Table 1).

Table 2 shows unadjusted sociopsychological factor status, visit behaviors, and colorectal cancer screening by study group. Previsit, tailored IMCP recipients had more favorable scores than control group participants for knowledge of screening harms and inconveniences,
Figure 2. Flow of participants through the trial.

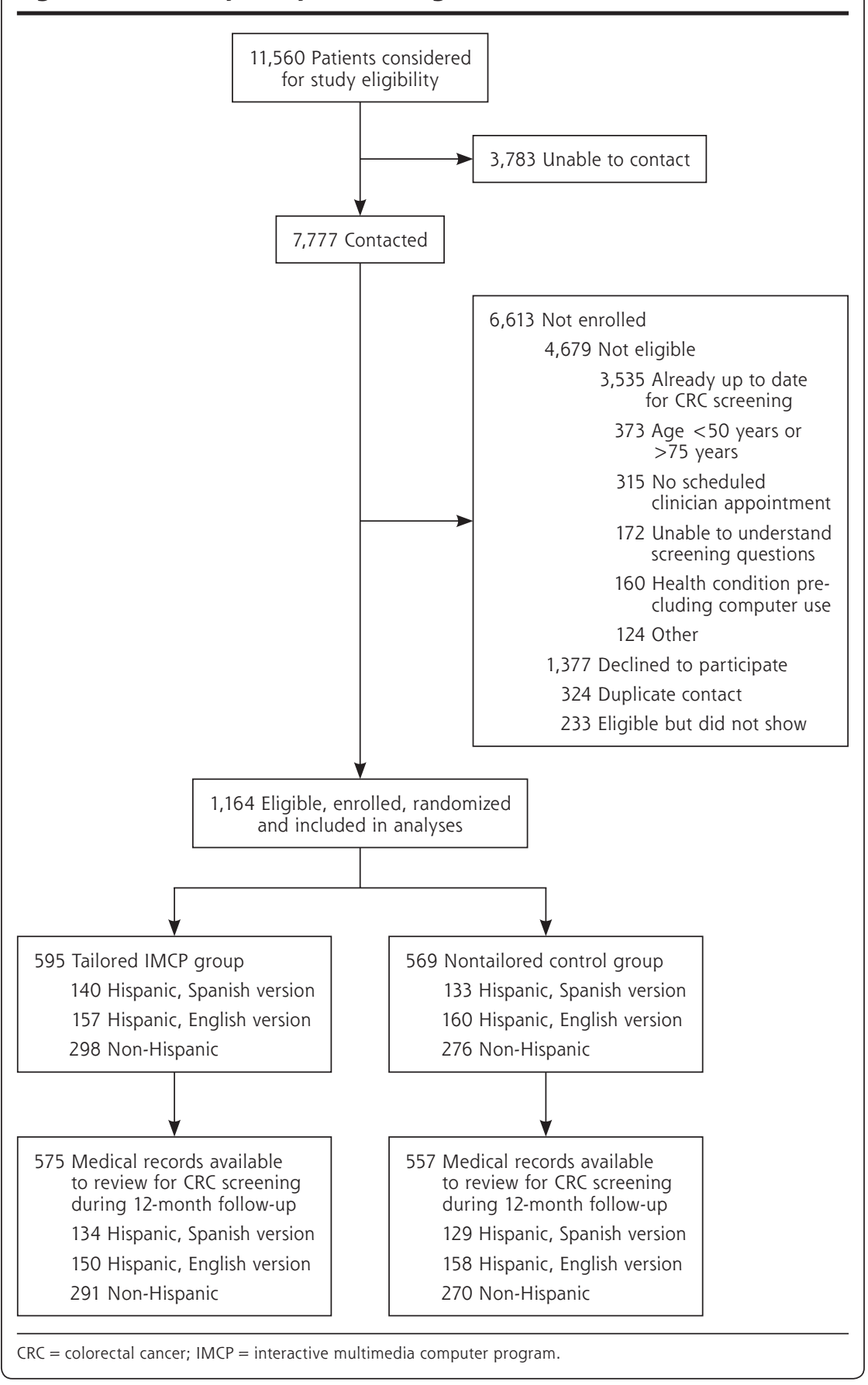


Table 1. Characteristics of the Participants by Study Group

\begin{tabular}{|c|c|c|c|c|c|}
\hline \multirow[b]{2}{*}{ Characteristics } & \multicolumn{2}{|c|}{$\begin{array}{l}\text { Study Intervention } \\
\text { Group }^{\mathrm{a}}\end{array}$} & \multirow[b]{2}{*}{ Characteristics } & \multicolumn{2}{|c|}{$\begin{array}{c}\text { Study Intervention } \\
\text { Group }^{\mathrm{a}}\end{array}$} \\
\hline & $\begin{array}{l}\text { Control } \\
\mathrm{N}=569\end{array}$ & $\begin{array}{l}\text { Tailored } \\
\text { IMCP } \\
\mathbf{N}=595\end{array}$ & & $\begin{array}{l}\text { Control } \\
\mathrm{N}=569\end{array}$ & $\begin{array}{l}\text { Tailored } \\
\text { IMCP } \\
\mathbf{N}=595\end{array}$ \\
\hline \multirow{2}{*}{$\begin{array}{l}\text { Patient enrollment by perfor- } \\
\text { mance site, } \%\end{array}$} & & & \multicolumn{3}{|l|}{ Education level, \% } \\
\hline & & & $<$ High school & 15.8 & 19.0 \\
\hline Rochester, New York & 20.9 & 21.0 & Some high school & 21.5 & 18.1 \\
\hline Bronx, New York & 24.0 & 24.1 & High school graduate & 25.1 & 23.8 \\
\hline Denver and Southwestern Colorado & 15.6 & 16.0 & Some college & 18.5 & 20.9 \\
\hline San Antonio, Texas & 17.9 & 16.7 & College graduate & 19.0 & 18.3 \\
\hline Sacramento, California & 21.6 & 22.2 & \multicolumn{3}{|l|}{ Income level, \% } \\
\hline \multicolumn{3}{|l|}{ Sociodemographics } & $<\$ 10,000$ & 33.2 & 35.0 \\
\hline Age, mean (SD), y & $57.1(6.2)$ & $57.0(6.1)$ & $\$ 10,000$ to $<\$ 15,000$ & 18.9 & 17.8 \\
\hline Female, \% & 65.8 & 65.0 & $\$ 15,000$ to $<\$ 25,000$ & 17.8 & 14.7 \\
\hline $\begin{array}{l}\text { Spanish language version } \\
\text { of software, \% }\end{array}$ & 23.5 & 23.4 & $\$ 25,000$ to $<\$ 50,000$ & 14.5 & 15.3 \\
\hline \multicolumn{3}{|l|}{ Ethnicity/race category, \% } & $>\$ 50,000$ & 15.6 & 17.2 \\
\hline Hispanic (any race) & 51.5 & 49.7 & $\begin{array}{l}\text { Self-rated health literacy } \\
\text { (range 1-5), mean (SD) }\end{array}$ & $2.0(1.2)$ & $2.1(1.3)$ \\
\hline Non-Hispanic & & & \multicolumn{3}{|l|}{ Health-related characteristics } \\
\hline White & 20.7 & 21.0 & \multirow{2}{*}{$\begin{array}{l}\text { Health status score (range 0-100), } \\
\text { mean (SD) }\end{array}$} & & \\
\hline Black & 23.0 & 24.9 & & & \\
\hline Other race & 4.7 & 4.4 & SF-12 physical component summary & $42.9(11.1)$ & $42.1(11.7)$ \\
\hline \multicolumn{3}{|l|}{ Country of birth, $\%$} & SF-12 mental component summary & $45.4(11.4)$ & $45.5(11.3)$ \\
\hline United States & 69.2 & 70.6 & \multirow{2}{*}{\multicolumn{3}{|c|}{$\begin{array}{l}\text { Duration of current primary care } \\
\text { clinician relationship, } \%\end{array}$}} \\
\hline Argentina & 9.5 & 7.6 & & & \\
\hline Dominican Republic & 7.7 & 9.6 & $<1 \mathrm{y}$ & 26.3 & 24.6 \\
\hline Mexico & 7.7 & 8.2 & $1-2 y$ & 18.9 & 16.8 \\
\hline Puerto Rico & 5.8 & 4.0 & $3-5$ y & 15.6 & 19.9 \\
\hline \multirow{2}{*}{\multicolumn{3}{|c|}{$\begin{array}{l}\text { Length of time living in United } \\
\text { States, \%b }\end{array}$}} & $>5 y$ & 36.1 & 36.5 \\
\hline & & & Unsure & 3.0 & 2.2 \\
\hline$<1 \mathrm{y}$ & 4.0 & 6.9 & \multicolumn{3}{|l|}{ Intervention factors } \\
\hline $1-5 y$ & 8.0 & 11.4 & Software use time, mean (SD), mine & $32.5(22.2)$ & $33.1(21.8)$ \\
\hline $6-10 y$ & 8.6 & 9.7 & \multirow{2}{*}{$\begin{array}{l}\text { Satisfaction with software score } \\
(\text { range 1-5), mean (SD) }\end{array}$} & \multirow[t]{2}{*}{$4.2(0.5)$} & \multirow[t]{2}{*}{$4.3(0.5)$} \\
\hline$>10 y$ & 79.4 & 72.0 & & & \\
\hline \multicolumn{6}{|c|}{$\mathrm{IMCP}=$ interactive multimedia computer program. } \\
\hline \multicolumn{6}{|c|}{$\begin{array}{l}\text { a } P>.10 \text { for all comparisons of characteristics between groups }\left(x^{2} \text { test for cate }\right. \\
\text { b Calculated using data from the } 350 \text { respondents ( } 175 \text { control, } 175 \text { tailored I } \\
\text { ' Higher scores indicate lower self-assessed health literacy. } \\
\text { d Higher scores indicate better health. } \\
\text { e Based on available data from } 550 \text { control patients and } 572 \text { IMCP patients. } \\
\text { ' Higher scores indicate greater satisfaction. }\end{array}$} \\
\hline
\end{tabular}

total screening knowledge, and self-efficacy. Postvisit, IMCP recipients again had more favorable scores than control group participants for these measures, as well as for knowledge of test options and specific test preference. Visit discussion and clinician recommendation of screening (but not screening during follow-up) were more likely in the tailored IMCP group.

Table 3 shows the adjusted effects of the tailored IMCP on EHBM factors and visit behaviors. Compared with the control group, IMCP exposure led participants to higher screening knowledge, self-efficacy, and stage of readiness, a greater likelihood of preferring a specific test option, as well as more reported discussion and clinician recommendation of screening. There were no significant IMCP effects on FOBT or colonoscopy barriers. There were no significant interactions between intervention and ethnicity/language in influencing outcomes (data not shown, available upon request). Among Hispanic persons, however, IMCP effects on EHBM factors were limited to greater knowledge, readiness, and specific test preference in the stratum preferring English. There were no significant IMCP effects on screening discussion or recommendation in the Hispanic strata.

Among 1,132 (97\%) patients with available medical records, the tailored IMCP had no greater effect than 
Table 2. Unadjusted Expanded Health Belief Model Sociopsychological Factor Status, Patient and Provider Visit Behaviors, and Colorectal Cancer Screening by Study Group

\begin{tabular}{|c|c|c|c|c|c|}
\hline \multirow[b]{2}{*}{ Characteristics $(\mathrm{N}=1,164)$} & \multicolumn{2}{|c|}{ Intervention Group } & \multirow[b]{2}{*}{ Characteristics $(\mathrm{N}=1,164)$} & \multicolumn{2}{|c|}{ Intervention Group } \\
\hline & $\begin{array}{l}\text { Control } \\
(N=569)\end{array}$ & $\begin{array}{c}\text { Tailored } \\
\text { IMCP } \\
(N=595)\end{array}$ & & $\begin{array}{l}\text { Control } \\
(\mathrm{N}=569)\end{array}$ & $\begin{array}{c}\text { Tailored } \\
\text { IMCP } \\
(\mathrm{N}=595)\end{array}$ \\
\hline \multicolumn{3}{|l|}{ EHBM sociopsychological factors } & \multicolumn{3}{|l|}{ Colonoscopy } \\
\hline \multicolumn{3}{|l|}{ Specific test preference, \% } & Previsit & $3.4(0.7)$ & $3.5(0.6)$ \\
\hline Previsit & 62.6 & 64.5 & Postvisit & $3.5(0.7)$ & $3.5(0.7)$ \\
\hline Postvisit ${ }^{\mathrm{a}}$ & 76.3 & 83.2 & Stage of readiness, $\%$ d & & \\
\hline \multicolumn{3}{|l|}{ Screening knowledge score, mean (SD) } & Precontemplation & & \\
\hline \multicolumn{3}{|l|}{ Test options (score range $0-3)^{\mathrm{b}}$} & Previsit & 11.1 & 4.9 \\
\hline Previsit & $1.6(0.8)$ & $1.7(0.8)$ & Postvisit & 7.4 & 6.2 \\
\hline Postvisitc & $1.9(0.8)$ & $2.2(0.8)$ & Contemplation & & \\
\hline \multirow{2}{*}{\multicolumn{3}{|c|}{$\begin{array}{l}\text { Harms/inconveniences } \\
\quad(\text { score range } 0-6)^{b, d}\end{array}$}} & Previsit & 63.0 & 62.0 \\
\hline & & & Postvisit & 59.5 & 54.5 \\
\hline Previsitc & $3.7(2.1)$ & $4.3(2.1)$ & Preparation & & \\
\hline Postvisitc & $4.1(2.3)$ & $5.0(2.4)$ & Previsit & 25.9 & 33.0 \\
\hline \multicolumn{3}{|l|}{ Total (score range $0-9)^{b, e}$} & Postvisit & 33.0 & 39.4 \\
\hline Previsitc & $5.3(2.5)$ & $5.9(2.5)$ & Self-reported prior CRC screening, \% ${ }^{d}$ & & \\
\hline Postvisitc & $6.0(2.7)$ & $7.2(2.8)$ & FOBT & 26.5 & 26.9 \\
\hline \multicolumn{3}{|l|}{$\begin{array}{l}\text { Self-efficacy score (score range 1-5), } \\
\text { mean (SD) }\end{array}$} & Colonoscopy & 13.2 & 15.9 \\
\hline Previsitc & $3.8(0.7)$ & $4.1(0.7)$ & \multicolumn{3}{|l|}{ Patient-reported visit behaviors, \% } \\
\hline Postvisit ${ }^{\mathrm{a}}$ & $3.9(0.7)$ & $4.0(0.6)$ & CRC screening discussed & 34.8 & 41.2 \\
\hline \multirow{2}{*}{\multicolumn{3}{|c|}{$\begin{array}{l}\text { Barriers score (score range } 1-5), \\
\text { mean (SD) }\end{array}$}} & Clinician recommended CRC screening & 50.2 & 59.0 \\
\hline & & & CRC screening, No. (\%) & $123(22.1)$ & $132(23.0)$ \\
\hline \multicolumn{6}{|l|}{ FOBT } \\
\hline Previsit & $3.5(0.8)$ & $3.5(0.8)$ & & & \\
\hline Postvisit & $3.5(0.7)$ & $3.5(0.8)$ & & & \\
\hline \multicolumn{6}{|c|}{$\mathrm{CRC}=$ colorectal cancer; IMCP = interactive multimedia computer program; EHBM = expanded health belief model; FOBT = fecal occult blood testing. } \\
\hline \multicolumn{6}{|l|}{ a $P<.01}$. \\
\hline \multicolumn{6}{|c|}{${ }^{c} P<.001$ for difference in scores between intervention groups ( $c^{2}$ test for categorical variables, $t$ test for continuous variables). } \\
\hline \multicolumn{6}{|c|}{$\begin{array}{l}\text { In the tailored IMCP group, these questions were answered after participants had viewed some information tailored to their knowledge of colorectal cancer screening } \\
\text { options (see Methods and Figure } 1 \text { for details). }\end{array}$} \\
\hline \multicolumn{6}{|c|}{ e Total knowledge score is sum of scores for knowledge of screening test options and knowledge of screening harms and inconveniences scales. } \\
\hline \multicolumn{6}{|c|}{${ }^{f}$ Higher scores indicate higher self-efficacy. } \\
\hline \multicolumn{6}{|l|}{${ }^{g}$ Higher scores indicate fewer barriers. } \\
\hline h During 12 months of follow-up, based on re & medical re & available $\mathrm{fc}$ & 2 participants (575 IMCP patients, 557 co & & \\
\hline
\end{tabular}

control on colorectal cancer screening (Table 3). Figure 3 shows the Kaplan-Meier curves for screening in both study groups during 12 months follow-up.

\section{DISCUSSION}

An IMCP tailored to EHBM sociopsychological factors was no more effective than a nontailored informational program in improving objectively measured colorectal cancer screening even though the IMCP successfully enhanced most of the EHBM factors and both targeted visit behaviors, all previously associated with screening. Of previous randomized controlled trials comparing a sociopsychologically tailored colorectal cancer screening intervention with an active control, ${ }_{1}^{15,19,20,22,25-30,33}$ only some reported improvements in screening ${ }^{19,25,28,29,34}$ in most instances based on patient report, ${ }_{1}^{19,25,28,29}$ suggesting possible misclassification bias. These observations, plus our current findings, raise doubts about the superiority of sociopsychological tailoring to nontailored approaches in promoting colorectal cancer screening.

Only 1 previous trial of colorectal cancer screening included sociopsychological tailoring in a multiethnic sample as part of a multifaceted intervention, but it did not examine tailoring effects specifically. ${ }^{25}$ The effects of our IMCP on sociopsychological factors and visit behaviors did not differ significantly among ethnicity/ language strata. Although this finding might suggest sociopsychological tailoring holds promise for reducing screening disparities, the lack of superior IMCP effects on screening indicates that promise remains 


\section{Table 3. Adjusted Effects of the Tailored Intervention (vs Control) on Postvisit Sociopsychological} Factors, Visit Behaviors, and Colorectal Cancer Screening

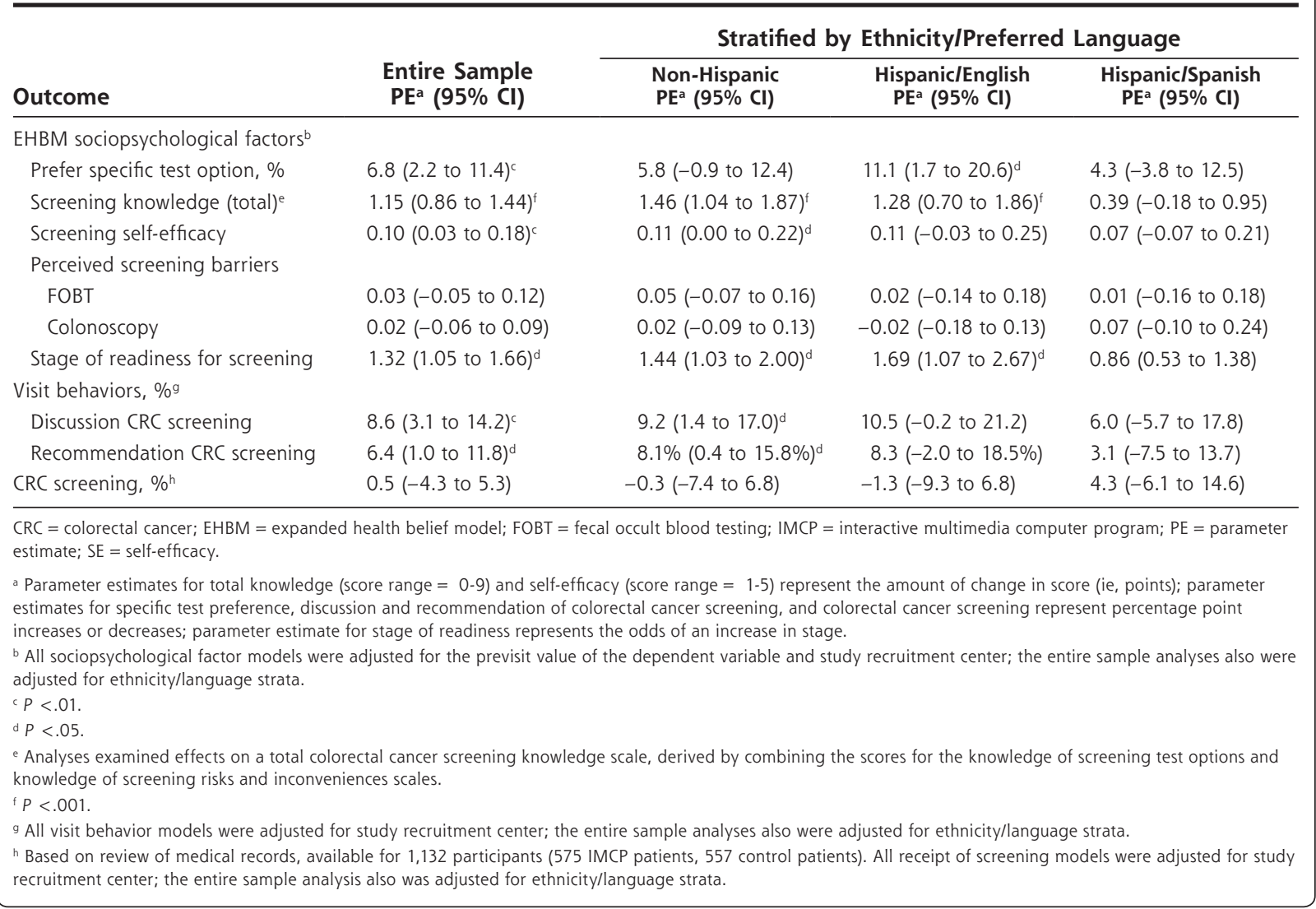

unfulfilled. The greater simplicity and lower cost of the nontailored control compared with the IMCP intervention, coupled with its similar behavioral effects, suggests that wider use of one-time computer-delivered sociopsychological tailoring may not be cost-effective. Others have reached similar conclusions. ${ }^{56}$

One possible explanation for the lack of superior effects of sociopsychological tailoring on screening is that EHBM factors are insufficiently enhanced. Previsit sociopsychological factor scores were favorable in our sample, leaving relatively little room for improvement. There was no significant effect of the tailored IMCP on screening barriers, and the effect sizes for the other EHBM factors and visit behaviors were small. For example, compared with control, the IMCP produced a $0.16 \mathrm{SD}$ increase in self-efficacy; effect sizes around 0.2 are generally viewed as small..$^{57}$ Nonetheless, these EHBM factor effect sizes are comparable to those in published trials. ${ }^{10-22}$

In our sample, a $1 \mathrm{SD}$ increase in self-efficacy was associated with a $5.4 \%$ greater likelihood of screening (data not shown, available upon request). Thus, the IMCP self-efficacy effect size of 0.16 would be expected to translate into a less than $1 \%$ increase in screening $(5.4 \% \times 0.16=0.86 \%)$. The small estimated IMCP effect on screening is consistent with the findings of prior tailoring trials, most of which focused on EHBM factors. In 2 meta-analyses of randomized controlled trials examining sociopsychological tailoring effects on health behaviors (almost exclusively self-reported), the estimated mean behavioral effect sizes were 0.074 (95\% CI, 0.066-0.082) and 0.17 (95\% CI, 0.14-0.19). ${ }^{23,24}$ In this context, our findings suggest the need to study the behavioral effects of tailoring to sociopsychological factors other than those in the EHBM. Several promising candidates exist, such as regulatory focus and preference for autonomysupportive (vs directive) communication. ${ }^{58,59}$

It may also be that enhancement of complex, temporally far-removed behaviors is too much to expect from a single, brief, computerized tailoring exposure. Weeks to months of delay are common subsequent to a clinician's order for colorectal cancer screening, particularly for colonoscopy ${ }_{1}^{60}$ the most frequently utilized test in our sample and nationally. ${ }^{61}$ We did not serially measure the status of sociopsychological factors, but the salutary effects of tailoring on these factors likely waned with time. Our experience suggests 


\section{Figure 3. Kaplan-Meier curve for receipt of colorectal cancer screening after intervention according to study group.}

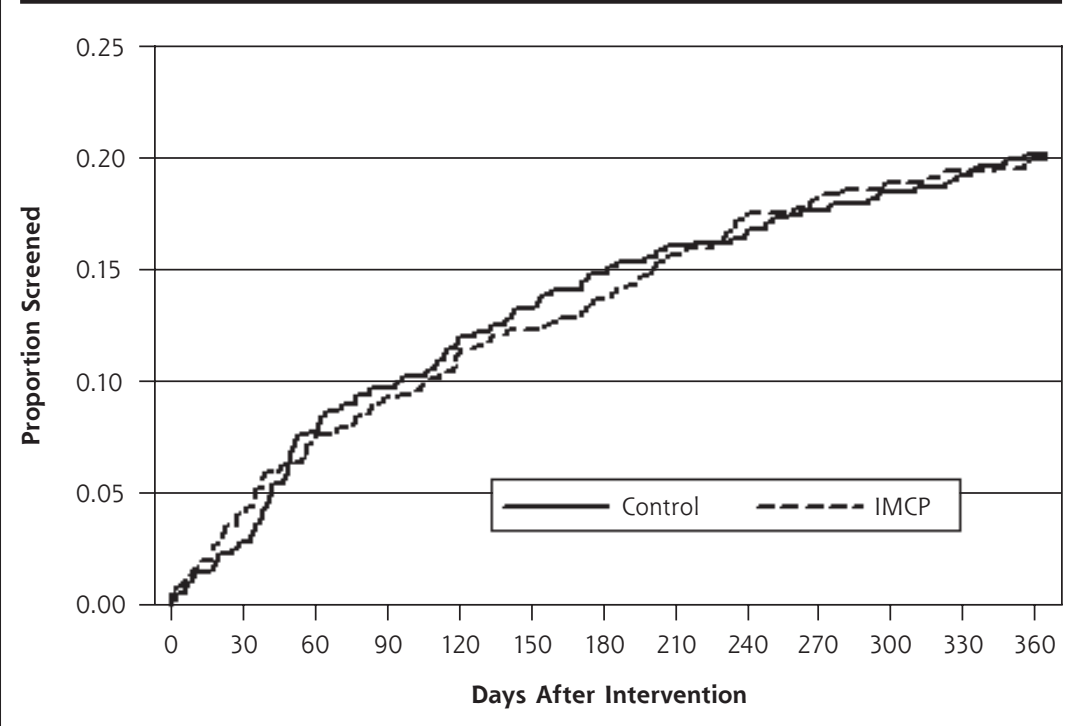

$\mathrm{IMCP}=$ interactive multimedia computer program.

Note: Screening was ascertained by medical record review.

that one-time computerized tailoring may favorably influence immediate sociopsychological and behavioral outcomes, including acceptance of initial care for depression during a linked office visit. ${ }^{62}$ By contrast, promoting such behaviors as colorectal cancer screening may require repeated tailoring exposures (eg, via the Internet or telephone texting) or linkage with other approaches (eg, reminder e-mails, telephone care management, clinician-focused interventions). ${ }^{63-65}$

Another possible explanation for the lack of tailoring effects on screening is that the IMCP did not address cultural factors, especially those affecting Hispanic participants. Even so, although differences in screening between ethnicity/language groups were not statistically significant, the IMCP effect on screening was largest in the Hispanic/Spanish group (Table 3). IMCP effects on sociopsychological factors and visit behaviors also were similar among ethnicity/language groups (Table 3), with no significant intervention*ethnicity/language interaction. Furthermore, research suggests that EHBM sociopsychological factors are relevant across cultural groups. ${ }^{25,36}$

Our study had limitations. Randomization by patient was used for feasibility but may have diluted the intervention effects had study clinicians interacting with IMCP patients treated control patients differently. Record documentation may have been missing for some screened patients, so the screening rates reported here are likely conservative. Still, because rates of missing study data should not differ by study group, compari- sons of screening between groups should not have been affected. We measured the study visit behaviors using patient report, which is subject to biases. Alternative methods of assessing visit behaviors also have limitations. For example, clinician reports may also be biased, and observing or recording visits may change the behaviors. In the tailored IMCP (but not control) group, the previsit measures of some EHBM factors were not true baseline (preintervention) measures (Figure 1). As a result, previsit imbalances favored the IMCP group for the knowledge of screening harms and inconveniences and selfefficacy measures (Table 2), leaving less room for improvement in these factors. Because analyses of IMCP effects on these factors are biased toward the null, our estimates for these factors may be conservative.

In conclusion, 1-time EHBM sociopsychological factor tailoring delivered by an IMCP was no more effective than nontailored information in encouraging objectively measured colorectal cancer screening in a multiethnic sample, despite salutary effects on sociopsychological factors and visit behaviors predictive of screening. Furthermore, IMCP effects did not differ significantly among ethnicity and preferred language subgroups. The findings raise doubts regarding the utility of single-exposure sociopsychological factor tailoring in promoting and reducing ethnic disparities in colorectal cancer screening.

To read or post commentaries in response to this article, see it online at http://www.annfammed.org/content/12/3/204.

Key words: colorectal neoplasms; computer-assisted instruction; early detection of cancer; expanded health belief model; health behavior; health care disparities; health education; health promotion; Hispanic Americans; outcome and process assessment (health care); patient acceptance of health care; randomized controlled trial; software

Submitted June 14, 2013; submitted, revised, December 10, 2013, accepted December 28, 2013.

Author affiliations: Department of Family and Community Medicine, University of California Davis, Sacramento, California (Jerant, Franks); Center for Healthcare Policy and Research, University of California Davis, Sacramento, California (Jerant, Kravitz ,Tancredi, Franks); Division of General Internal Medicine, University of California Davis, Sacramento, California (Kravitz); Department of Community Health and Social Medicine, Sophie Davis School of Biomedical Education of The City College 
of New York, New York, New York (Sohler); Department of Family Medicine and Community and Preventive Medicine, University of Rochester, Rochester, New York (Fiscella); Department of Family and Community Medicine, University of Texas Health Science Center at San Antonio, San Antonio, Texas (Romero); Department of Family Medicine, University of Colorado, Denver, Colorado (Parnes); Department of Pediatrics, University of California Davis, Sacramento, California (Tancredi); Department of Internal Medicine, University of California Davis, Sacramento, California (Aguilar-Gaxiola); Center for Reducing Health Disparities, University of California Davis, Sacramento, California (Aguilar-Gaxiola); University of California Davis Medical Center, Sacramento, California (Slee); IETAcademic Technology Services, University of California Davis, Davis, California (Dvorak, Turner); Sutter Medical Foundation, Sacramento, California (Hudnut, Prieto).

Funding support: This work was funded in part by the National Cancer Institute (R01CA131386) and the American Recovery and Reinvestment Act (CA13138602S1).

Disclaimer: The funders had no role in the design and conduct of the study; the collection, management, analysis, and interpretation of the data; the preparation, review, or approval of the manuscript; or the decision to submit the manuscript for publication.

Acknowledgments: We are grateful to the following individuals, who facilitated recruitment and participation of patients in the study: Dionne Evans-Dean, MHA, Dustin Gottfeld, BS, Lizette Macias, BS, Lori Reid, RN, and Linda Marks, MPA (Sacramento); Mechelle R. Sanders, BA and Leticia E. Serrano, AAS (Rochester); Sandra Monroy, MA (New York City); and Brandon Tutt, MA (Colorado). We also wish to thank Robert Burnett, MA, for his programming contributions to the tailored software program. Finally, we are indebted to all of the primary care offices and patients who participated.

\section{ClinicalTrials.gov identifier: NCT00786747}

\section{References}

1. Klabunde CN, Cronin KA, Breen N, Waldron WR, Ambs AH, Nadel MR. Trends in colorectal cancer test use among vulnerable populations in the United States. Cancer Epidemiol Biomarkers Prev. 2011; 20(8):1611-1621.

2. U.S. Preventive Services Task Force. Screening for colorectal cancer: U.S. Preventive Services Task Force recommendation statement. Ann Intern Med. 2008;149(9):627-637.

3. Jerant AF, Arellanes RE, Franks P. Factors associated with Hispanic/ non-Hispanic white colorectal cancer screening disparities. J Gen Intern Med. 2008;23(8):1241-1245.

4. Rosenstock IM, Strecher VJ, Becker MH. Social learning theory and the health belief model. Health Educ Q. 1988;15(2):175-183.

5. Sabatino SA, Lawrence B, Elder R, et al; Community Preventive Services Task Force. Effectiveness of interventions to increase screening for breast, cervical, and colorectal cancers: nine updated systematic reviews for the guide to community preventive services. Am J Prev Med. 2012;43(1):97-118.

6. Chua RY, lyengar SS. Empowerment through choice? A critical analysis of the effects of choice in organizations. Res Organ Behav. 2006;27:41-79.

7. Hawkins RP, Kreuter M, Resnicow K, Fishbein M, Dijkstra A. Understanding tailoring in communicating about health. Health Educ Res. 2008;23(3):454-466.

8. Jerant A, Sohler N, Fiscella K, Franks B, Franks P. Tailored interactive multimedia computer programs to reduce health disparities: opportunities and challenges. Patient Educ Couns. 2011;85(2):323-330.
9. Petty RE, Cacioppo JT. Communication and Persuasion: Central and Peripheral Routes to Attitude Change. New York, NY: Springer-Verlag; 1986.

10. Jerant A, Kravitz RL, Rooney M, Amerson S, Kreuter M, Franks P. Effects of a tailored interactive multimedia computer program on determinants of colorectal cancer screening: a randomized controlled pilot study in physician offices. Patient Educ Couns. 2007;66 (1):67-74.

11. Rawl SM, Skinner CS, Perkins SM, et al. Computer-delivered tailored intervention improves colon cancer screening knowledge and health beliefs of African-Americans. Health Educ Res. 2012;27(5):868-885.

12. Mosher CE, Fuemmeler BF, Sloane R, et al. Change in self-efficacy partially mediates the effects of the FRESH START intervention on cancer survivors' dietary outcomes. Psychooncology. 2008;17(10): 1014-1023.

13. Napolitano MA, Papandonatos GD, Lewis BA, et al. Mediators of physical activity behavior change: a multivariate approach. Health Psychol. 2008;27(4):409-418.

14. Emmons KM, Wong M, Puleo E, Weinstein N, Fletcher R, Colditz $G$. Tailored computer-based cancer risk communication: correcting colorectal cancer risk perception. J Health Commun. 2004;9(2): 127-141.

15. Costanza ME, Luckmann R, Stoddard AM, et al. Using tailored telephone counseling to accelerate the adoption of colorectal cancer screening. Cancer Detect Prev. 2007;31(3):191-198.

16. Myers RE, Hyslop T, Sifri R, et al. Tailored navigation in colorectal cancer screening. Med Care. 2008;46(9)(Suppl 1):S123-S131.

17. Christy SM, Perkins SM, Tong Y, et al. Promoting colorectal cancer screening discussion: a randomized controlled trial. Am J Prev Med. 2013;44(4):325-329.

18. Glenn BA, Herrmann AK, Crespi CM, et al. Changes in risk perceptions in relation to self-reported colorectal cancer screening among first-degree relatives of colorectal cancer cases enrolled in a randomized trial. Health Psychol. 2011;30(4):481-491.

19. Ruffin MT IV, Fetters MD, Jimbo M. Preference-based electronic decision aid to promote colorectal cancer screening: results of a randomized controlled trial. Prev Med. 2007;45(4):267-273.

20. Miller DP Jr, Spangler JG, Case LD, Goff DC Jr, Singh S, Pignone MP. Effectiveness of a web-based colorectal cancer screening patient decision aid: a randomized controlled trial in a mixedliteracy population. Am J Prev Med. 2011;40(6):608-615.

21. Kukafka R, Lussier YA, Eng P, Patel VL, Cimino JJ. Web-based tailoring and its effect on self-efficacy: results from the MI-HEART randomized controlled trial. Proc AMIA Symp. 2002;410-414.

22. Rawl SM, Champion VL, Scott LL, et al. A randomized trial of two print interventions to increase colon cancer screening among firstdegree relatives. Patient Educ Couns. 2008;71(2):215-227.

23. Krebs P, Prochaska JO, Rossi JS. A meta-analysis of computertailored interventions for health behavior change. Prev Med. 2010; 51(3-4):214-221.

24. Noar SM, Benac CN, Harris MS. Does tailoring matter? Metaanalytic review of tailored print health behavior change interventions. Psychol Bull. 2007;133(4):673-693.

25. Walsh JM, Salazar R, Nguyen TT, et al. Healthy colon, healthy life: a novel colorectal cancer screening intervention. Am J Prev Med. 2010;39(1):1-14.

26. Vernon SW, Bartholomew LK, McQueen A, et al. A randomized controlled trial of a tailored interactive computer-delivered intervention to promote colorectal cancer screening: sometimes more is just the same. Ann Behav Med. 2011;41(3):284-299.

27. Myers RE, Sifri R, Hyslop T, et al. A randomized controlled trial of the impact of targeted and tailored interventions on colorectal cancer screening. Cancer. 2007;110(9):2083-2091. 
28. Manne SL, Coups EJ, Markowitz A, et al. A randomized trial of generic versus tailored interventions to increase colorectal cancer screening among intermediate risk siblings. Ann Behav Med. 2009; 37(2):207-217.

29. Marcus AC, Mason M, Wolfe $P$, et al. The efficacy of tailored print materials in promoting colorectal cancer screening: results from a randomized trial involving callers to the National Cancer Institute's Cancer Information Service. J Health Commun. 2005;10(Suppl 1):83-104.

30. Weinberg DS, Keenan E, Ruth K, Devarajan K, Rodoletz M, Bieber EJ. A randomized comparison of print and web communication on colorectal cancer screening. JAMA Intern Med. 2013;173(2):122-129.

31. Neville LM, O'Hara B, Milat AJ. Computer-tailored dietary behaviour change interventions: a systematic review. Health Educ Res. 2009;24(4):699-720.

32. Rimer BK, Conaway M, Lyna P, et al. The impact of tailored interventions on a community health center population. Patient Educ Couns. 1999;37(2):125-140.

33. Myers RE, Bittner-Fagan H, Daskalakis C, et al. A randomized controlled trial of a tailored navigation and a standard intervention in colorectal cancer screening. Cancer Epidemiol Biomarkers Prev. 2013; 22(1):109-117.

34. Menon $\mathrm{U}$, Belue $\mathrm{R}$, Wahab $\mathrm{S}$, et al. A randomized trial comparing the effect of two phone-based interventions on colorectal cancer screening adherence. Ann Behav Med. 2011;42(3):294-303.

35. Fenton JJ, Jerant AF, von Friederichs-Fitzwater MM, Tancredi DJ, Franks P. Physician counseling for colorectal cancer screening: impact on patient attitudes, beliefs, and behavior. J Am Board Fam Med. 2011;24(6):673-681.

36. Cameron KA, Francis L, Wolf MS, Baker DW, Makoul G. Investigating Hispanic/Latino perceptions about colorectal cancer screening: a community-based approach to effective message design. Patient Educ Couns. 2007;68(2):145-152.

37. American Cancer Society. Guidelines for the early detection of cancer. 2013. http://www.cancer.org/Healthy/FindCancerEarly/ CancerScreeningGuidelines/american-cancer-society-guidelinesfor-the-early-detection-of-cancer.

38. Schulz KF, Grimes DA. Generation of allocation sequences in randomised trials: chance, not choice. Lancet. 2002;359(9305):515-519.

39. Pressman RS. Software Engineering: A Practitioner's Approach. 6 th ed. New York, NY: McGraw-Hill; 2005.

40. Jerant A, Kravitz RL, Fiscella K, et al. Effects of tailored knowledge enhancement on colorectal cancer screening preference across ethnic and language groups. Patient Educ Couns. 2013;90(1):103-110.

41. O'Connor AM, Fiset V, DeGrasse C, et al. Decision aids for patients considering options affecting cancer outcomes: evidence of efficacy and policy implications. J Natl Cancer Inst Monogr. 1999;25(25):67-80.

42. Kreuter M, Farrell D, Olevitch L, Brennan L. Tailoring Health Messages: Customizing Communication With Computer Technology. Mahwah, NJ: Lawrence Erlbaum Associates; 2000.

43. Deci EL, Ryan RM. The support of autonomy and the control of behavior. J Pers Soc Psychol. 1987;53(6):1024-1037.

44. Miller SM. Monitoring versus blunting styles of coping with cancer influence the information patients want and need about their disease. Implications for cancer screening and management. Cancer. 1995;76(2):167-177.

45. Peterson C, Stunkard AJ. Personal control and health promotion. Soc Sci Med. 1989;28(8):819-828.

46. Freed $E$, Long $D$, Rodriguez $T$, Franks $P$, Kravitz RL, Jerant $A$. The effects of two health information texts on patient recognition memory: a randomized controlled trial. Patient Educ Couns. 2013;92(2): 260-265.
47. National Cancer Institute. Tests to detect colorectal cancer and polyps. 2011. http://www.cancer.gov/cancertopics/factsheet/detection/ colorectal-screening.

48. Instituto Nacional del Cáncer. Exámenes para detectar el cáncer colorrectal y los pólipos. 2011. http://www.cancer.gov/espanol/recursos/ hojas-informativas/deteccion-diagnostico/examenes-colorrectal.

49. O'Connor AM. User manual - knowledge. 2000. Ottawa Hospital Research Institute. http://decisionaid.ohri.ca/docs/develop/User_ Manuals/UM_Knowledge.pdf.

50. Vernon SW, Myers RE, Tilley BC. Development and validation of an instrument to measure factors related to colorectal cancer screening adherence. Cancer Epidemiol Biomarkers Prev. 1997;6(10):825-832.

51. O'Connor AM. User manual - decision self-efficacy scale. 1995. Ottawa Hospital Research Institute. http://decisionaid.ohri.ca/docs/ develop/User_Manuals/UM_Decision_SelfEfficacy.pdf.

52. Rawl S, Champion V, Menon U, Loehrer PJ, Vance GH, Skinner CS. Validation of scales to measure benefits of and barriers to colorectal cancer screening. J Psychosoc Oncol. 2001;19:47-63.

53. Prochaska JO, Goldstein MG. Process of smoking cessation. Implications for clinicians. Clin Chest Med. 1991;12(4):727-735.

54. Morris NS, MacLean CD, Chew LD, Littenberg B. The Single Item Literacy Screener: evaluation of a brief instrument to identify limited reading ability. BMC Fam Pract. 2006;7:21.

55. Ware J Jr, Kosinski M, Keller SD. A 12-Item Short-Form Health Survey: construction of scales and preliminary tests of reliability and validity. Med Care. 1996;34(3):220-233.

56. Lairson DR, DiCarlo M, Myers RE, et al. Cost-effectiveness of targeted and tailored interventions on colorectal cancer screening use. Cancer. 2008;112(4):779-788.

57. Cohen J. Statistical Power Analysis For the Behavioral Sciences. 2nd ed. Hillsdale, NJ: Erlbaum; 1988.

58. Resnicow K, Davis RE, Zhang G, et al. Tailoring a fruit and vegetable intervention on novel motivational constructs: results of a randomized study. Ann Behav Med. 2008;35(2):159-169.

59. Cesario J, Grant H, Higgins ET. Regulatory fit and persuasion: transfer from "Feeling Right". J Pers Soc Psychol. 2004;86(3):388-404.

60. Denberg TD, Melhado TV, Coombes JM, et al. Predictors of nonadherence to screening colonoscopy. J Gen Intern Med. 2005;20 (11):989-995.

61. Jerant AF, Fenton JJ, Franks P. Determinants of racial/ethnic colorectal cancer screening disparities. Arch Intern Med. 2008;168(12):1317-1324.

62. Kravitz RL, Franks P, Feldman MD, et al. Patient engagement programs for recognition and initial treatment of depression in primary care: a randomized trial. JAMA. 2013;310(17):1818-1828.

63. Dietrich AJ, Tobin JN, Cassells A, et al. Telephone care management to improve cancer screening among low-income women: a randomized, controlled trial. Ann Intern Med. 2006;144(8):563-571.

64. Ferreira MR, Dolan NC, Fitzgibbon ML, et al. Health care providerdirected intervention to increase colorectal cancer screening among veterans: results of a randomized controlled trial. J Clin Oncol. 2005;23(7):1548-1554.

65. Schneider F, de Vries H, Candel M, van de Kar A, van Osch L. Periodic email prompts to re-use an internet-delivered computertailored lifestyle program: influence of prompt content and timing. J Med Internet Res. 2013;15(1):e23. 